\title{
Isotopic Scaling of Transport in Deuterium-Tritium Plasmas
}

\author{
S.D. Scott, D. R. Ernst, M. Murakami $†$ H. Adler, M. G. Bell, \\ R. Bell, R. V. Budny, C. E. Bush†, Z. Chang; H. Duong§ \\ L. R. Grisham, E. D. Fredrickson, B. Grek, R. J. Hawryluk, \\ K. W. Hill, J. Hosea, D. L. Jassby, D. W. Johnson, \\ L. C. Johnson, M. J. Loughlin, D. K. Mansfield, K. M. McGuire, \\ D. M. Meade, D. M. Mikkelsen, J. Murphy, H. K. Park, A. T. Ramsey, \\ J. Schivell, C. H. Skinner, J. D. Strachan, E. J. Synakowski, \\ G. Taylor, M. E. Thompson, R. Wieland, and M. C. Zarnstorff
}

\author{
Plasma Physics Laboratory \\ Princeton University \\ P. O. Box 451 \\ Princeton, NJ, USA 08543
}

\section{PPPL-3001}

October 1994

This paper was presented at the Workshop in Fusion Plasmas, Aspenäs, Göteborg, Sweden (June 1994) and has been submitted for publication in Physica Scripta.

* Massachusetts Institute of Technology, Cambridge, MA

tOak Ridge National Laboratory, Oak Ridge, TN

‡University of Wisconsin, Madison, WI

§University of California, Irvine, CA

IJET Joint Undertaking, Abingdon, United Kingdom

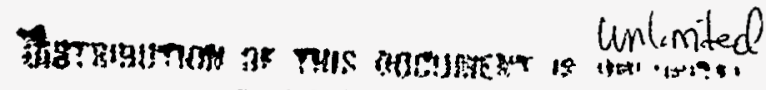
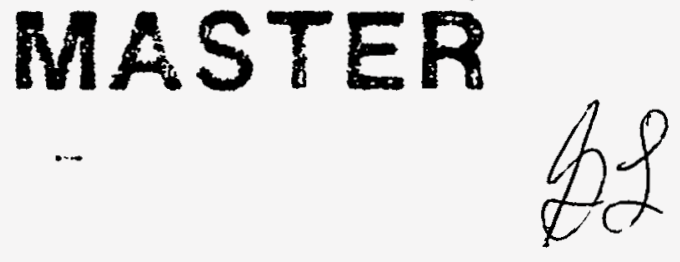


\section{DISCLAIMER}

This report was prepared as an account of work sponsored by an agency of the United States Government. Neither the United States Government nor any agency thereof, nor any of their employees, make any warranty, express or implied, or assumes any legal liability or responsibility for the accuracy, completeness, or usefulness of any information, apparatus, product, or process disclosed, or represents that its use would not infringe privately owned rights. Reference herein to any specific commercial product, process, or service by trade name, trademark, manufacturer, or otherwise does not necessarily constitute or imply its endorsement, recommendation, or favoring by the United States Government or any agency thereof. The views and opinions of authors expressed herein do not necessarily state or reflect those of the United States Government or any agency thereof. 


\section{DISCLAIMER}

Portions of this document may be illegible in electronic image products. Images are produced from the best available original document. 


\section{Abstract}

Both global and thermal energy confinement improve in high-temperature supershot plasmas in the Tokamak Fusion Test Reactor (TFTR) when deuterium beam heating is partially or wholly replaced by tritium beam heating. For the same heating power, the tritium-rich plasmas obtain up to $22 \%$ higher total energy, $30 \%$ higher thermal ion energy, and $20-25 \%$ higher central ion temperature. Kinetic analysis of the temperature and density profiles indicates a favorable isotopic scaling of ion heat transport and electron particle transport, with $\tau_{E i}(a / 2) \propto\langle A\rangle^{0.7-0.8}$ and $\tau_{p e}(a) \propto\langle A\rangle^{0.8}$. 


\section{Introduction}

The variation of energy confinement with isotopic composition has been studied in many tokamaks over the past two decades, primarily by comparing hydrogen, deuterium, and helium plasmas. In this paper we compare heat and particle transport in high temperature beamfueled deuterium TFTR plasmas to those with mixed deuterium-tritium or pure tritium beam fueling. For the same heating power, the total plasma energy $\left(W_{\text {tot }}\right)$ as measured by magnetic diagnostics is up to $22 \%$ higher in plasmas fueled with tritium beams relative to comparable deuterium plasmas. Some of this increase can be attributed to simple classical effects such as energy stored in the unthermalized fusion alpha component and the increased energy stored in unthermalized beam ions during tritium beam injection. Up to $60 \%$ of the total increase in $W_{\text {tot }}$ arises from additional energy stored in the thermal ions and electrons, indicating a favorable dependence of $\tau_{E}$ on isotopic composition in these plasmas. In particular, the most tritium-rich plasmas experience a $20-25 \%$ increase in central ion temperature, a $30 \%$ increase in energy stored in the thermal ions, and a $35 \%$ reduction in ion thermal diffusivity. Electron particle transport is improved by a comparable factor, while the change in electron temperature and electron thermal diffusivity appear to be smaller.

The range of isotopic mass explored in these experiments is rather limited due to deuterium influx from the limiter $\left[\langle A\rangle \equiv\left(n_{h}+2 n_{d}+3 n_{t}\right) /\left(n_{h}+n_{d}+n_{t}\right) \approx 1.9 \rightarrow 2.6\right]$. The observed confinement improvement between deuterium and nominally tritium plasmas therefore implies a rather strong isotopic dependence, with $\tau_{E}$ (magnetic) varying as $\langle A\rangle^{2 / 3}$ and $\tau_{E i}(a / 2)$ varying as $\langle A\rangle^{0.7-0.8}$.

\section{Discharge conditions}

These experiments were conducted in TFTR supershot plasmas, which are characterized by high ion temperatures $(\sim 30 \mathrm{keV})$, peaked electron density profiles, and relatively low influx of hydrogenic neutrals from the limiter[1]. The plasmas were members of three experimental DT campaigns, designated here as $A, B$, and $C$, which span a modest range in heating power and limiter conditioning. A mixture of deuterium and tritium neutral beams with energies 90-107 keV were injected to both heat and fuel the discharge. The 12 beam sources were aimed in toroidally opposed directions to yield little net toroidal momentum input to the plasma. A major consideration in the design of these experiments was to obtain matched scans of deuterium (DD) and deuterium-tritium (DT) plasmas whose conditions were as similar as possible with the exception of tritium concentration. Table 1 summarizes the plasma conditions in these scans and the variation in limiter conditioning between DD and DT plasmas. Generally this variation was limited to less than $5 \%$ in carbon influx (only a $\pm 1 \%$ variation for scan $\mathrm{C} 1$ ), which corresponds to less than a $2 \%$ uncontrolled variation in $\tau_{E}$.

The scan members were selected to have similar low m,n MHD between DD and DT plasmas. However, there remains some variability in the time evolution of the MHD in these plasmas, particularly in scans A1 and A2. Based on correlations of low $\mathrm{m} / \mathrm{n}$ MHD amplitude with $\tau_{E}$ in previous supershot experiments[2], the observed MHD in the DD and DT plasmas of Table 1 was responsible for a reduction in $W_{\text {tot }}$ of less than $\sim 3 \%$ at $3.45 \mathrm{sec}$, and less than $\sim 5 \%$ at $3.60 \mathrm{sec}$. To ensure that the inferred isotopic scaling of heat transport is not affected by MHD, we focus on analysis early in the beam heating pulse (450-600 ms), before the MHD grows to sufficient amplitude to significantly affect the transport. This also avoids possible deterioration of confinement associated with the enhanced deuterium influx in the DT plasmas, which could be responsible for a $9 \%$ reduction in $\tau_{E}$, based on previously observed correlations of $\tau_{E}$ and limiter recycling in supershots. 


\begin{tabular}{|c|c|c|c|c|c|c|c|c|c|c|}
\hline \multirow{2}{*}{$\begin{array}{r}\text { Scan Sym } I_{p} \\
(\mathrm{MA})\end{array}$} & Pulse & $P_{b}$ & $P_{t} / P_{b}$ & $B_{c o}$ & \multicolumn{4}{|c|}{ Ohmic target conditions } & \multirow[t]{2}{*}{$\Delta W / W$} & \multirow[t]{2}{*}{$\operatorname{Tr}$} \\
\hline & & \multicolumn{3}{|c|}{$(\mathrm{MW})$} & \multicolumn{4}{|c|}{\begin{tabular}{l|ll}
$\mathrm{Li}$ & $\Delta C_{I I} \Delta H_{\alpha}$ & $\Delta \bar{n}_{e}$ \\
\end{tabular}} & & \\
\hline \multirow[t]{3}{*}{$\mathrm{A} 1 \mathrm{O}$} & 73265 & 29.7 & 0.00 & -0.02 & 2 & - & - & - & -0.07 & $\sqrt{ }$ \\
\hline & 73255 & 29.2 & 0.48 & 0.10 & 2 & -0.04 & 0.00 & -0.03 & - & $\sqrt{ }$ \\
\hline & 73268 & 29.6 & 0.66 & 0.08 & 2 & 0.03 & 0.01 & 0.02 & -0.10 & $\sqrt{ }$ \\
\hline \multirow[t]{3}{*}{$\mathrm{A} 2 \diamond 1.98$} & 73262 & 27.5 & 0.00 & 0.07 & 1 & - & - & - & -0.06 & $\sqrt{ }$ \\
\hline & 73254 & 26.7 & 0.44 & 0.00 & 2 & -0.04 & -0.05 & -0.05 & -0.08 & $\sqrt{ }$ \\
\hline & 73258 & 26.8 & 0.53 & 0.04 & 1 & -0.01 & 0.01 & -0.02 & -0.07 & $\sqrt{ }$ \\
\hline \multirow[t]{3}{*}{ B1 $\triangle 1.78$} & 73459 & 22.7 & 0.00 & 0.33 & 0 & - & - & - & -0.05 & $\sqrt{ }$ \\
\hline & 73446 & 22.1 & 0.67 & 0.23 & 0 & 0.02 & -0.03 & 0.01 & -0.08 & $\sqrt{ }$ \\
\hline & 73450 & 23.0 & 1.00 & 0.24 & 0 & -0.03 & 0.00 & 0.02 & -0.14 & - \\
\hline \multirow[t]{3}{*}{$\mathrm{B} 2$} & $\underline{73449}$ & 20.5 & 0.00 & 0.26 & 0 & - & $\overline{-}$ & - & -0.03 & $\sqrt{ }$ \\
\hline & 73452 & 20.2 & 0.74 & 0.15 & 0 & 0.00 & 0.07 & 0.00 & -0.03 & $\sqrt{ }$ \\
\hline & 73447 & 20.9 & 1.00 & 0.15 & 0 & -0.04 & -0.01 & -0.02 & -0.03 & $\sqrt{ }$ \\
\hline \multirow[t]{4}{*}{$\mathrm{C} 1 \bigcirc \quad \mathrm{O} \quad 1.97$} & 75925 & 26.6 & 0.00 & 0.06 & 0 & - & - & - & - & $\sqrt{ }$ \\
\hline & 75926 & 28.5 & 0.56 & 0.05 & 0 & 0.01 & -0.03 & 0.01 & - & $\sqrt{ }$ \\
\hline & 75932 & 29.0 & 0.55 & 0.04 & 0 & 0.00 & -0.04 & 0.01 & - & $\sqrt{ }$ \\
\hline & 75941 & 28.9 & 0.47 & 0.06 & 0 & 0.01 & 0.01 & 0.03 & - & $\sqrt{ }$ \\
\hline
\end{tabular}

Table 1: Scans of tritium beam fueling in otherwise similar plasma discharges. All plasmas have $R=2.52 \mathrm{~m}$, $a=0.87 \mathrm{~m}, B_{t}=4.98$ Tesla. Underlined shot numbers represent the deuterium "reference" discharges which best match conditions in the deuterium-tritium discharges. 'Sym' indicates the symbol type used to identify scan members in the figures. $B_{c o}=\left(\Gamma_{c o}-\Gamma_{c t r}\right) /\left(\Gamma_{c o}+\Gamma_{c t r}\right)$ defines the beam torque fraction $[-1=$ counter, 0 $=$ balanced, $1=$ pure co-injection]. ' $\mathrm{Li}$ ' indicates the number of lithium pellets injected into previous discharge. Columns under the "Ohmic target conditions" show the fractional difference between each discharge and the reference deuterium discharge in carbon influx, hydrogenic influx, and line-averaged electron density just prior to start of beam injection. $\Delta W / W$ is the fractional change in total stored energy between the peak and the end of beam heating. A check $(V)$ in the last column identifies plasmas whose results are included in the regression analysis. 


\section{Typical DD and DT Performance}

Fig. I illustrates the time evolution of DD plasma 73265 versus DT plasma 73268 of scan A1 for which tritium neutral beams delivered $66 \%$ of the total beam power. The most striking difference is the $22 \%$ increase in total plasma stored energy in the DT plasma. There is a substantial, sustained increase in the central ion temperature and a somewhat smaller increase in central electron temperature, as measured by an ECE diagnostic, which is delayed in time relative to the increase in $T_{i o}$. The deuterium discharge 73265 had no significant coherent MHD activity, while the DT discharge suffered from a growing $\mathrm{m} / \mathrm{n}=4 / 3$ mode starting at 3.4 seconds, which could be responsible for a $10 \%$ loss of $W_{\text {tot }}$ by the end of the heating pulse. The DD and DT plasmas have very nearly the same evolution of the central electron density and chord-integrated visible bremsstrahlung emission, implying similar $Z_{\text {eff }}$. Deuterium neutral influx from the limiter, as indicated by the edge $H \alpha$ light emission, is very similar for the two plasmas for the first $450 \mathrm{~ms}$ of beam heating. Beyond that time the DT plasma suffers from as much as $18 \%$ more hydrogenic influx, which may also contribute to the deteriorating energy confinement.

Measured profiles of temperature and density for these plasmas are shown in Fig. 2. This figure illustrates several features that are common to most of the DD/DT plasma comparisons. First, the central ion temperature is significantly larger in the DT plasma, and $T_{i}$ remains visibly larger across much of the plasma cross-section. The electron density profiles are similar, with comparable values of the central electron density, and slightly larger edge densities in the DT plasma. The electron temperature profile measured by ECE is also higher in the DT plasma, although this trend is consistently less pronounced in the $T_{e}(R)$ profiles measured by Thomson scattering.

Table 2 summarizes the results of transport analysis for several pairs of DD and DT plasmas, including the discharges shown in Fig. 1 and 2. About $40-45 \%$ of the total energy increase observed between DD and DT plasmas can be attributed directly to changes in the beam-ion and alpha population. The remaining $55-60 \%$ arises from an increase in the integrated energy density of thermal ions and electrons. Since the total alpha heating in these plasmas is at most $\sim 1 \mathrm{MW}$ or $\sim 4 \%$ of the total beam power, the increased energy stored in the thermal plasma suggests that thermal energy confinement is higher in DT plasmas.

\section{Global Confinement Scaling}

As a starting point for understanding the isotopic scaling of local heat transport, it is useful to assess the scaling of global $\tau_{E}$ as determined from the magnetic diagnostics alone. Figure 3 plots the ratio of $\tau_{E}$ in each discharge after $540 \mathrm{~ms}$ of beam heating to $\tau_{E}$ in the corresponding DD reference discharge, as a function of the fraction of beam power which was tritium and also as a function of the average hydrogenic mass. There is some variability in DT performance, e.g. the DT discharges with nominally equal levels of $D^{\circ}$ and $T^{\circ}$ beam injection experience increases in $\tau_{E}$ ranging from $6 \%$ to $17 \%$ compared to the reference DD plasmas. Nevertheless, $\tau_{E}$ determined from magnetic analysis correlates roughly with the tritium beam fraction, and the maximum increase of $26 \%$ was realized during pure tritium beam injection. Collectively, the data are fit by $\tau_{E} / \tau_{E}^{d d}=1.0+0.21 P_{t} / P_{b}$, which corresponds to a dependence $\tau_{E} \propto\langle A\rangle^{0.67 \pm 0.06}$. The isotopic scaling changes only slightly $\left(\tau_{E} \propto\langle A\rangle^{0.60}\right)$ if the $d / d t$ correction to $\tau_{E}$ is neglected (by defining $\tau_{E} \equiv W_{t o t} /\left(P_{b}+P_{O H}\right)$ ) because these plasmas are close to equilibrium at $3.5 \mathrm{sec}$, with $\dot{W}_{\text {tot }}$ typically being less than $6 \%$ of the heating power. Including alpha heating as a power source term decreases the isotopic scaling of $\tau_{E}$ only modestly, from $\propto\langle A\rangle^{0.67}$ to $\propto\langle A\rangle^{0.54}$. If, in addition, the alpha stored energy is 

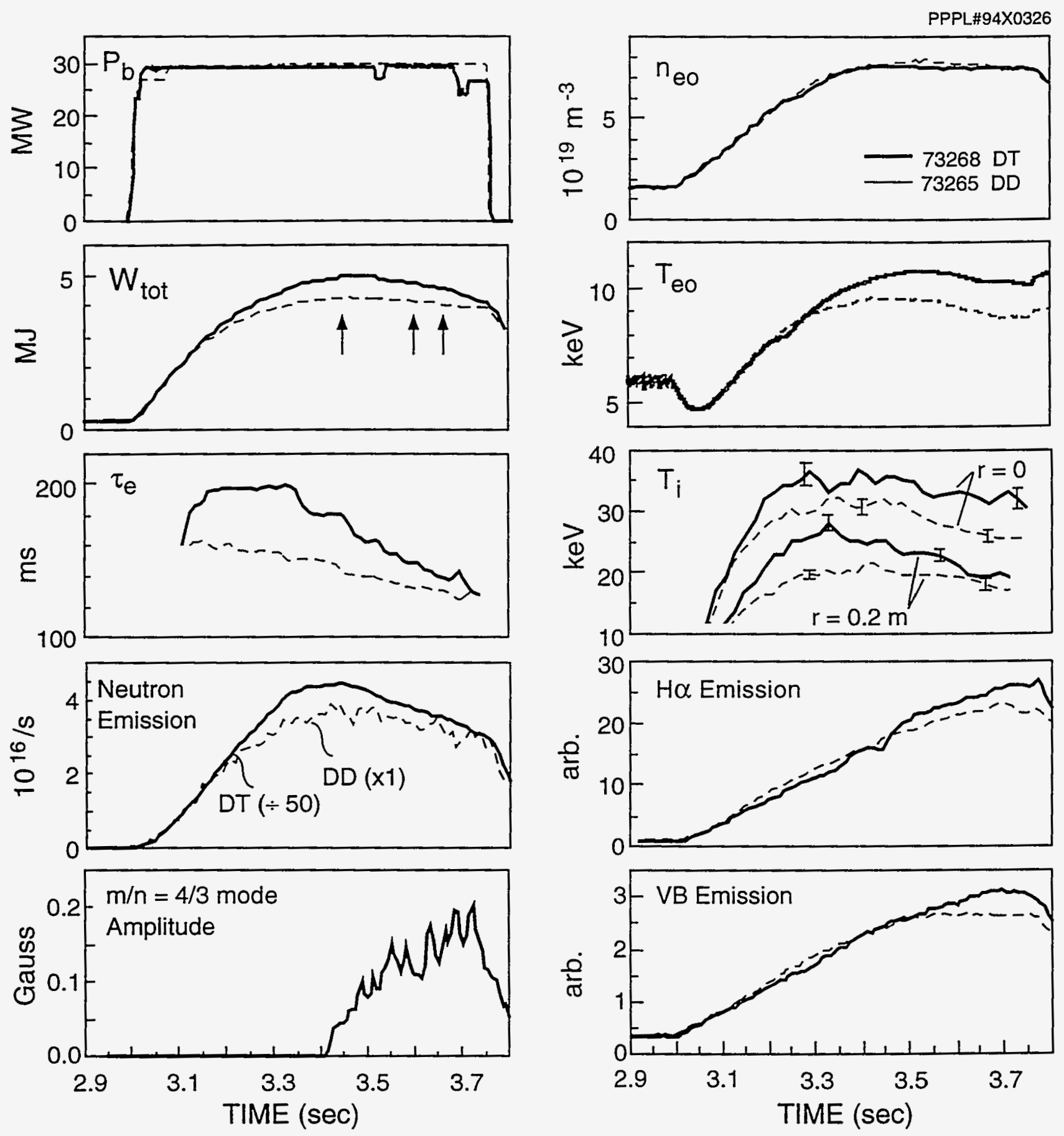

Figure 1: Time evolution of DD versus DT supershot plasmas 73265 and 73268 . Arrows indicate the times of steady-state transport analysis. 

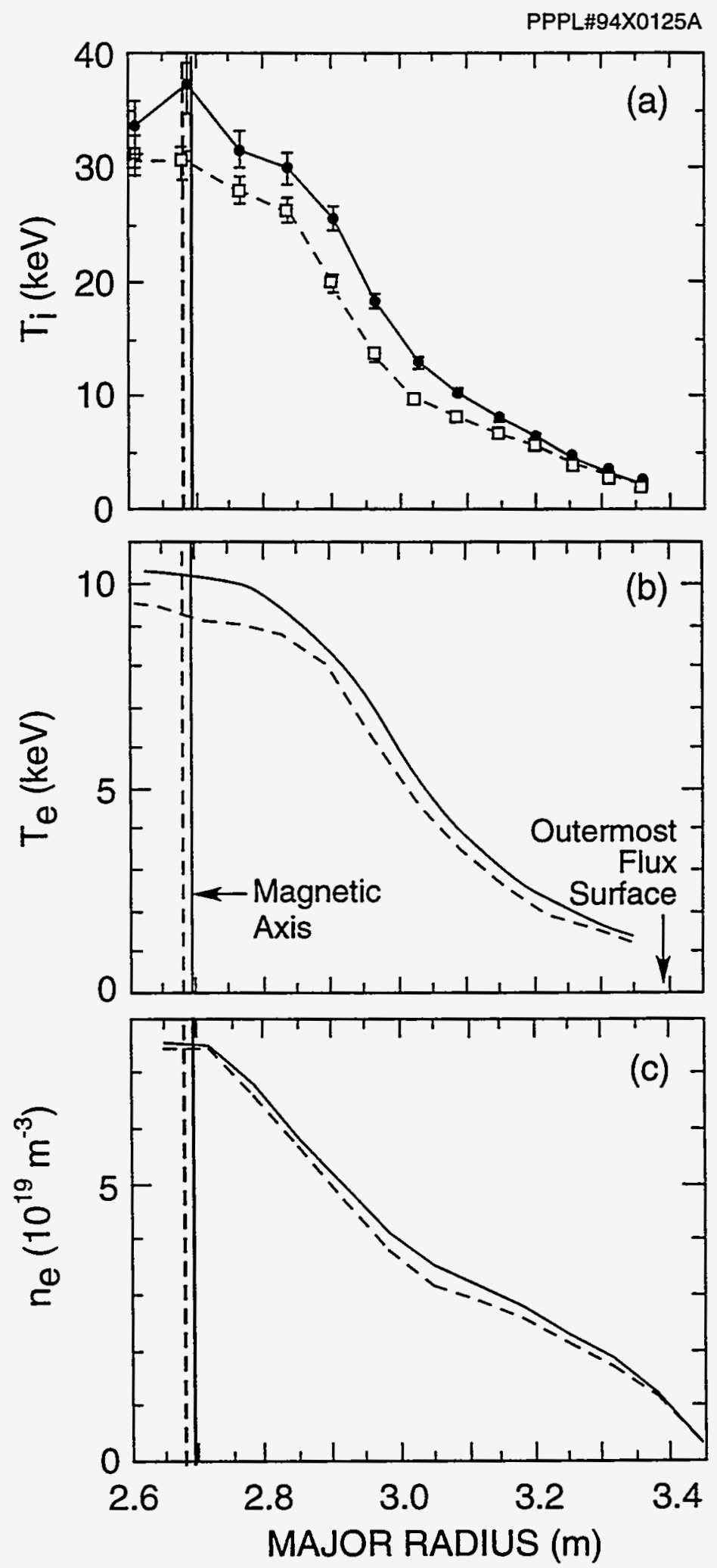

Figure 2: Measured ion and electron temperature profiles in DD versus DT supershot plasmas 73265 and 73268 after $450 \mathrm{~ms}$ of beam heating 


\begin{tabular}{||ll||lll||lll||ll||}
\hline \multicolumn{1}{|c||}{} & \multicolumn{3}{c||}{ Scan A1 } & \multicolumn{5}{c||}{ Scan C1 } \\
\hline Parameter & Units & DD & DT & $\Delta$ & DD & DT & $\Delta$ & DT & $\Delta$ \\
\hline$R$ & $\mathrm{~m}$ & 2.52 & 2.52 & & 2.52 & 2.52 & & 2.52 \\
$a$ & $\mathrm{~m}$ & 0.87 & 0.87 & 0.87 & 0.87 & 0.87 & \\
$B_{t}$ & Tesla & 4.95 & 4.95 & & 4.98 & 4.98 & & 4.98 & \\
$I_{p}$ & $\mathrm{MA}$ & 1.98 & 1.98 & & 1.97 & 1.97 & & 1.97 & \\
$q_{\psi}$ & & 4.70 & 4.98 & & 4.69 & 4.77 & & 4.77 \\
\hline$P_{b}$ (total) & $\mathrm{MW}$ & 29.7 & 29.6 & & 26.6 & 28.4 & & 28.9 & \\
$P_{t}$ & $\mathrm{MW}$ & 0 & 19.5 & & 0 & 16.0 & & 13.5 & \\
\hline$n_{\text {eo }}$ & $10^{19} \mathrm{~m}^{-3}$ & 7.65 & 7.57 & & 7.26 & 7.46 & & 7.46 & \\
$n_{h+d+t}$ & $10^{19} \mathrm{~m}^{-3}$ & 5.30 & 5.27 & & 4.64 & 4.83 & & 4.89 & \\
$Z_{\text {eff }}(0)$ & & 2.06 & 2.04 & & 2.22 & 2.24 & & 2.16 & \\
\hline$T_{\text {io }}$ & $\mathrm{keV}$ & 31.2 & 35.6 & & 21.6 & 25.2 & & 24.6 & \\
$T_{\text {eo }}$ & $\mathrm{keV}$ & 9.7 & 10.6 & & 9.0 & 10.0 & & 10.0 & \\
\hline$W_{i}$ & $\mathrm{MJ}$ & 1.33 & 1.63 & 0.30 & 1.04 & 1.23 & 0.19 & 1.36 & 0.32 \\
$W_{e}$ & $\mathrm{MJ}$ & 1.05 & 1.21 & 0.16 & 0.94 & 1.10 & 0.16 & 1.16 & 0.22 \\
$W_{\text {beam }}$ & $\mathrm{MJ}$ & 1.97 & 2.21 & 0.24 & 1.67 & 1.83 & 0.16 & 1.89 & 0.22 \\
$W_{\alpha}$ & $\mathrm{MJ}$ & 0. & 0.14 & 0.14 & 0 & 0.12 & 0.12 & 0.13 & 0.13 \\
$W_{\text {kin }}$ & $\mathrm{MJ}$ & 4.36 & 5.20 & 0.84 & 3.65 & 4.28 & 0.63 & 4.55 & 0.90 \\
$W_{\text {mag }}$ & $\mathrm{MJ}$ & 4.20 & 4.96 & 0.76 & 3.70 & 4.24 & 0.54 & 4.52 & 0.82 \\
\hline$P_{\text {dit-fusion }}$ & $\mathrm{MW}$ & - & 6.17 & & - & 4.71 & & 5.23 & \\
\hline Pulse & & 73265 & 73268 & & 75925 & 75926 & & 75941 & \\
\hline \hline
\end{tabular}

Table 2: DD and DT reference shots.

subtracted from the total stored energy, the isotopic scaling is reduced further, to $\tau_{E} \propto\langle A\rangle^{0.43}$.

\section{Kinetic Measurements and Analysis}

\section{Diagnostics}

The electron temperature profiles in these experiments were measured by two diagnostics: a 20-channel grating polychromator normalized to an absolutely calibrated Michelson interferometer, and a 76-channel Thomson scattering diagnostic. The electron density profile was measured by a 10-chord interferometer viewing the plasma vertically. The ion temperature and toroidal rotation profiles were measured by a charge-exchange recombination spectroscopy (CXRS) with viewing sightlines every $6 \mathrm{~cm} . Z_{\text {eff }}(R)$ profiles were obtained by measuring the chord-integrated visible bremsstrahlung emission with a 16-channel visible spectrometer array viewing tangentially in the horizontal midplane $\left(R_{\text {tan }}=1.70-3.42 \mathrm{~m}\right)$.

\section{SNAP Transport Model}

Local heat and particle transport coefficients are inferred from the measured profiles using the equilibrium transport code SNAP[3]. The beam-ion distribution function is calculated from a solution of the Fokker-Planck equation in the rotating plasma frame. The energy transport is analyzed assuming that the radial transport mechanisms are cross field diffusion, represented 

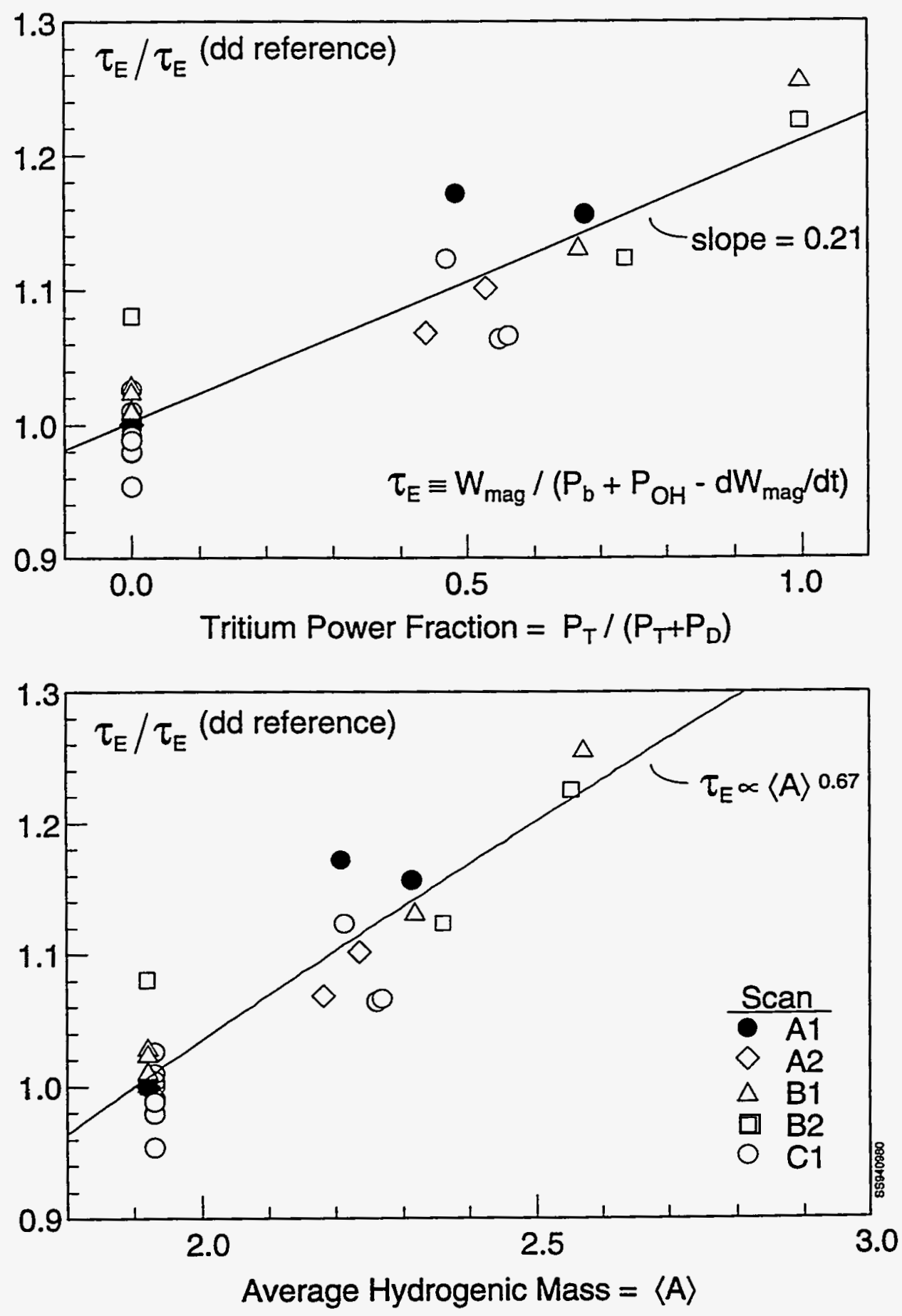

Figure 3: (a) Ratio of global energy confinement time measured by a diamagnetic loop and equilibrium magnetic diagnostics in DT plasmas to that in reference DD plasmas as a function of tritium-beam power fraction. (b) Same ratio plotted as a function of the average thermal hydrogenic mass. The symbols represent plasmas in different scans as defined in Table 1. 
by anomalous diffusivities $D_{e}, \chi_{i}$, and $\chi_{e}$ :

$$
\begin{array}{ll}
\Gamma_{e} \equiv-D_{e} \nabla n_{e} & \\
Q_{i} \equiv-\chi_{i}\left(\sum_{j} n_{j}\right) \nabla T_{i}+\frac{3}{2} \Gamma_{i} T_{i} & \equiv-\chi_{i}^{\text {tot }}\left(\sum_{j} n_{j}\right) \nabla T_{i} \\
Q_{e} \equiv-\chi_{e} n_{e} \nabla T_{e}+\frac{3}{2} \Gamma_{e} T_{e} & \equiv-\chi_{e}^{\text {tot }} n_{e} \nabla T_{e}
\end{array}
$$

where $Q_{i}$ and $Q_{e}$ are the total ion and electron heat flux, $\Gamma_{i}$ and $\Gamma_{e}$ are the ion and electron particle flux, $\sum_{j}$ represents a sum over all ion species including impurities, and $\chi_{i}^{\text {tot }}$ and $\chi_{e}^{\text {tot }}$ are "total" diffusivities which include both the convective and conductive fluxes.

The models of alpha particle heating and thermalization implemented in SNAP are similar to those used in its calculation of beam-ion physics. The raw alpha particle source rate is calculated as a function of minor radius from the $\mathrm{DT}$ fusion rate. Losses due to unconfined orbits and banana-trapped alpha particles whose banana tips lie in the stochastic ripple region are regarded as prompt-lost. The resulting confined, orbit-averaged alpha source rate is assumed to thermalize classically. This model agrees well ( $\Delta P_{\alpha} \leq 0.1 \mathrm{MW}, \Delta W_{\alpha} \leq 0.03 \mathrm{MJ}$ ) with more comprehensive TRANSP calculations which follow the guiding-center collisional orbits of an ensemble of thermalizing alpha particles.

\section{Plasma Composition}

The hydrogenic thermal ion density is determined in SNAP by subtracting the electron density associated with impurities and beam ions from the local measured electron density. The relative concentration of deuterium and tritium is determined by a simple model that is calibrated to give agreement with the measured DT neutron emission during injection of pure $T^{o}$ neutral beams. The model assumes fixed ratios of $n_{h}, n_{d}$, and $n_{t}$ across the entire plasma.

To assess the magnitude of the central deuterium concentration, the expected DT neutron emission was calculated as a function of deuterium concentration for discharges with trace tritium beam injection (11\%), $\sim 50 \%$, and $100 \%$ tritium beam injection. The relative deuterium and tritium concentrations are specified by the adjustable parameter $\Upsilon_{t}$, where $\frac{n_{t}}{n_{t}+n_{d}} \equiv \Upsilon_{t} \frac{P_{t}}{P_{t}+P_{d}}$ and $P_{t}$ and $P_{d}$ are the total tritium and deuterium beam power, respectively. As shown in Fig. 4, the calculated DT neutron emission approaches zero as $\Upsilon_{t}$ approaches 1.0 in plasmas with pure $T^{\circ}$ injection, since in this limit there is no deuterium in the plasma with which to fuse. For these discharges, the calculated neutron emission agrees with the measured emission for $\Upsilon_{t}$ values in the range 0.65-0.75. As discussed below, the accuracy of the calculated neutron emission in these plasmas is approximately $10 \%$, which corresponds to an uncertainty in the inferred value of $\Upsilon_{t}$ of order \pm 0.1 . For consistency, the relative tritium and deuterium concentrations for all plasmas in this experiment with mixed DT beam injection were determined using $\Upsilon_{t} \approx 0.65$.

As shown in Fig. 4, for plasmas with nominally equal amounts of tritium and deuterium beam power a variation of \pm 0.1 about the nominal value $\Upsilon_{t}=0.65$ should change the calculated neutron emission by only a few percent. For the DT discharge 73268 with $66 \%$ tritium beam fueling, calculations by the SNAP code indicate that varying $\Upsilon_{t}$ by \pm 0.1 changes the DT fusion power and unthermalized alpha energy by about $0.7 \%$, total stored plasma energy by less than $0.25 \%$, and $\chi_{e}^{\text {tot }}$ and $\chi_{i}^{\text {tot }}$ by less than $2 \%$ and $1 \%$, respectively, across the entire plasma cross section. Thus, uncertainties in the relative concentration of deuterium to tritium in these plasmas contribute only negligibly to the total uncertainty in the inferred local transport coefficients, largely because the alpha heating power is small relative to beam heating, and because in nominally 50:50 D:T plasmas the fusion rate is insensitive to variations in the relative deuterium to tritium concentration. 


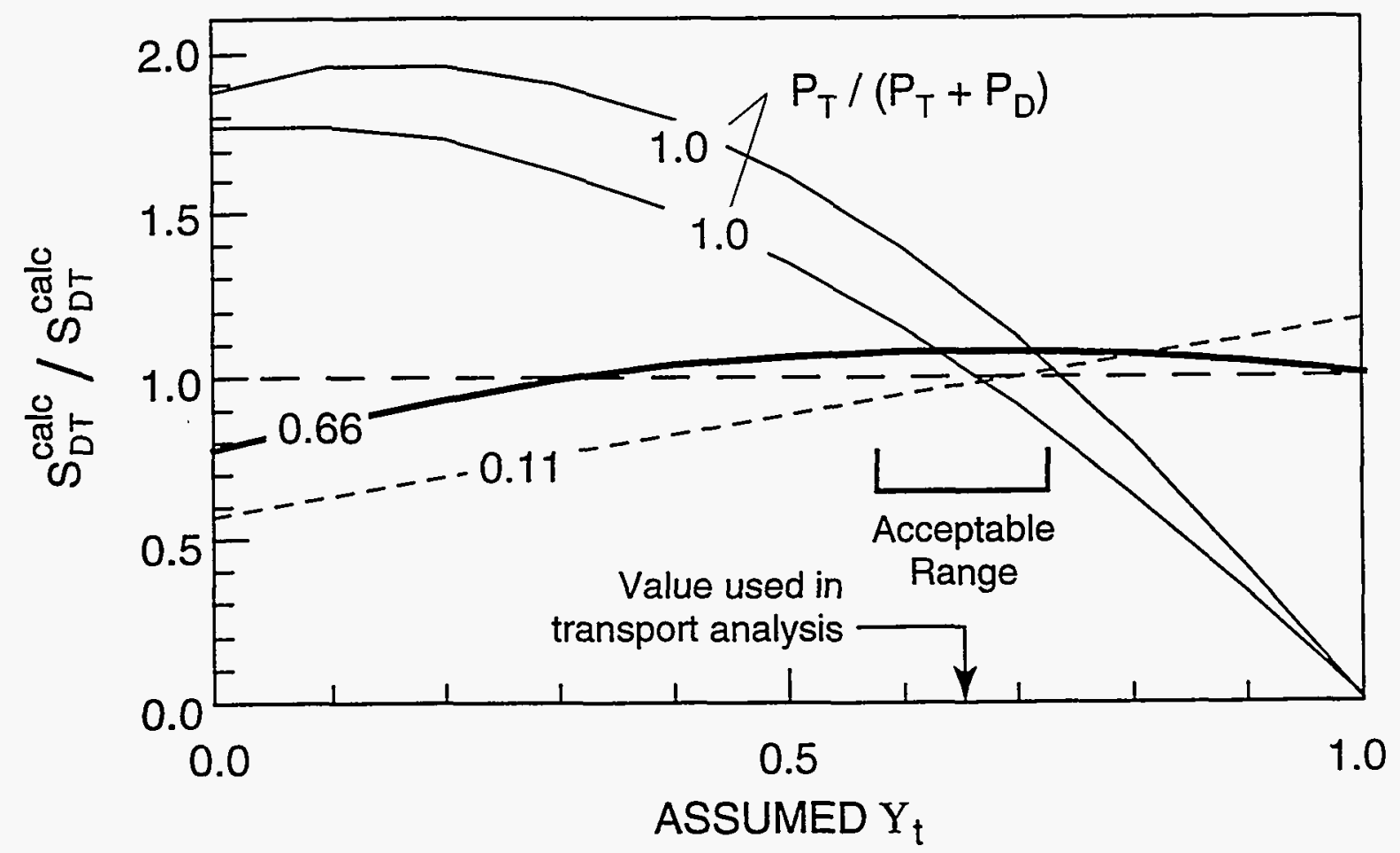

Figure 4: Ratio of DT neutron emission computed by SNAP to the measured neutron emission as a function of assumed $\Upsilon_{t}$ for plasmas with pure $T^{\circ}$-NBI, nominally equal $T^{o}$-NBI and $D^{o}$-NBI power, and trace (11\%) $T^{o}$-NBI beam injection.

\section{Power Deposition}

Because both the density profile and beam energy were very similar for the DD and DT plasmas, to first order the heating profiles are reasonably similar also. Figure 5 compares the calculated heating profiles of DD discharge 73265 to DT discharge 73268 . There is negligible difference in the beam power deposition profile to ions, because the poorer penetration of the tritium beam neutrals is partially compensated by the increased fraction of tritium beam power which is collisionally coupled to ions. By contrast, beam power deposition to electrons is reduced significantly in the plasma center, because both of these effects reduce beam power deposition to core electrons. However, this is offset by core heating of electrons by alpha particles and increased ion-electron coupling in the DT plasma. Overall, there are only small differences in the net heating profile between these DD and DT plasmas. Consequently, observed differences in temperature between them reflect differences in local transport properties.

Conduction is the dominant loss channel at the half radius for both ions and electrons. As is typically observed in supershot plasmas, the conducted losses become small near the plasma center, and particle convection becomes the dominant loss process, particularly for ions. Radiation is a significant loss channel for electrons only in the outer $15 \mathrm{~cm}$ of the plasma.

\section{Data Consistency}

To assess the data consistency among diagnostics in the high-neutron environment of DT experiments, we compare the results of kinetic analysis to direct diagnostic measurements of total stored energy and neutron emission. The overall stored-energy agreement is excellent, generally within $10 \%$, although the ratio $W_{k i n} / W_{\text {mag }}$ does tend to increase systematically with $P_{t} / P_{b}$, with the best fit to the data having a slope of 0.059 . Equivalent analysis performed 

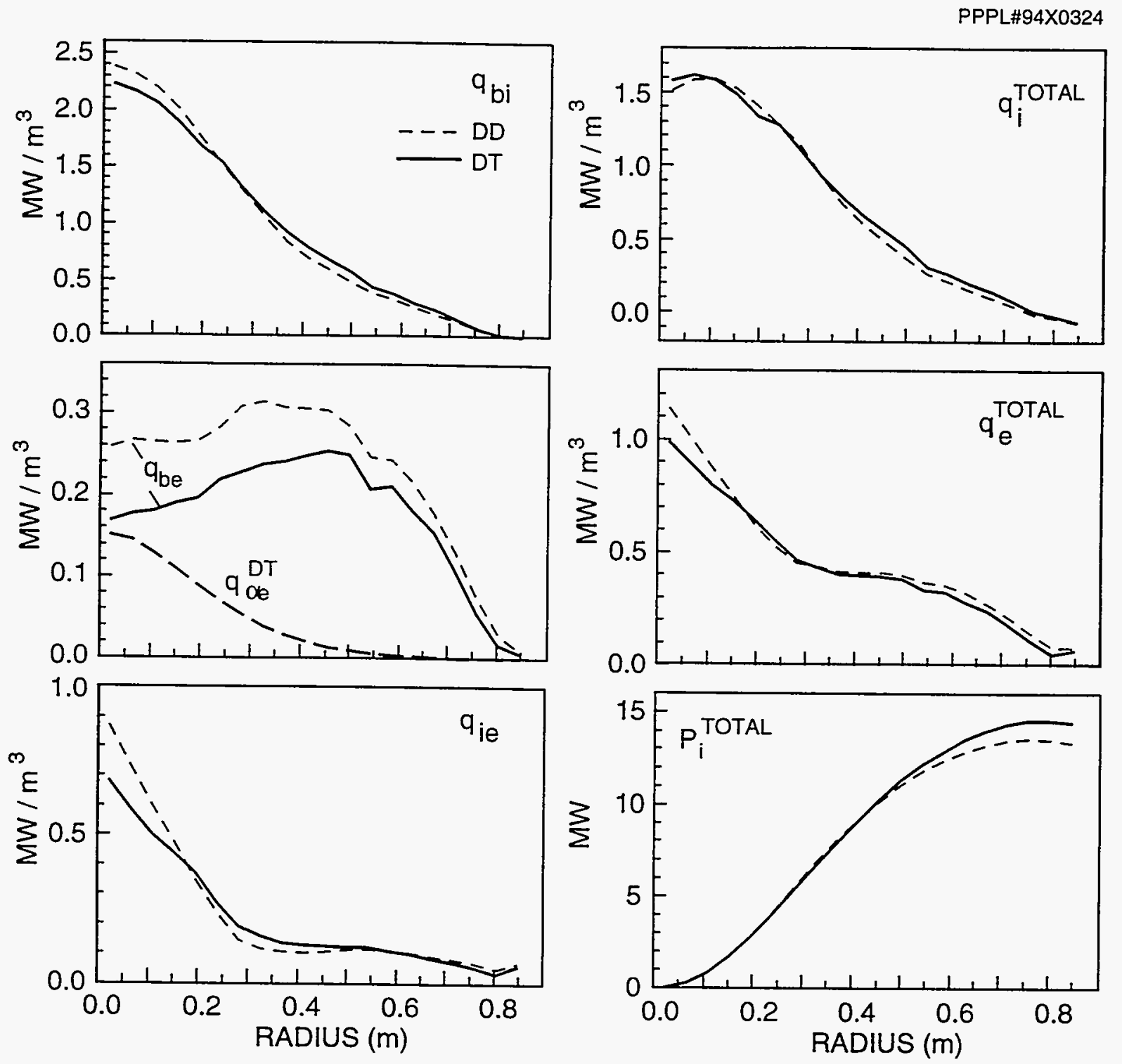

Figure 5: Comparison of calculated heating profiles in deuterium and deuterium-tritium plasmas. Here $q_{i}^{T O T A L} \equiv q_{b i}+q_{\alpha i}-q_{i e}+q_{v i s c o u s} ; q_{e}^{T O T A L} \equiv q_{b e}+q_{O H}+q_{\alpha e}+q_{i e}$, and $q_{b i}$ includes both beam collisional and thermalization power. 
for the ratio of the kinetic diamagnetic energy to that measured by a diamagnetic loop shows a weaker systematic bias of only $1.4 \%$. The measured $2.45 \mathrm{MeV}$ neutron emission from DD plasmas was $10-15 \%$ greater than that calculated by SNAP using the measured density and temperature profiles, while it was about $10 \%$ less than calculated in the DT discharges[4]. In both cases the discrepancy is comparable to the combined uncertainties of the kinetic prediction (10-13\%, based on estimated uncertainties in $T_{i}, T_{e}, n_{e}, Z_{\text {eff }}$, beam power, etc.) and the neutron measurement ( $\pm 13 \%$ for $2.45 \mathrm{MEV}$ neutron flux, and $\pm 7 \%$ for $14 \mathrm{MeV}$ neutron flux).

\section{Transport Analysis}

The results of the local transport analysis for these experiments is summarized in Figs. 6 and 7. Figure 6 plots the profile of the local ratio of $\chi_{i}^{\text {tot }}$ and $D_{e}$ in the DT plasma to reference DD plasma for three representative scans. In these plots, the reference DD data is represented by a horizonal line at $y=1$. The range of variation in similarly-prepared DD plasmas is represented by a shaded region. Over most of the plasma cross-section, $\chi_{i}^{\text {tot }}$ is lower in DT plasmas than in the reference DD plasma, and the difference is larger than the usual shot-toshot variation observed among similar DD discharges. The error bars shown in Fig. 6 represent the 1- $\sigma$ relative uncertainty in the diffusivity ratios arising from measurement error. Over most of the plasma cross-section, $\chi_{i}^{\text {tot }}$ in DT is more than 1- $\sigma$ below its value in the reference DD plasma, but typically not more than $2-\sigma$ less.

Averaged over the plasma cross-section, $\chi_{e}^{\text {tot }}$ is also slightly smaller $(\sim 15 \%$ in the DT plasma of scan AI) compared to the reference DD plasma. This is consistent with TRANSP analysis of the same discharges[5], which showed that the measured $T_{e}(r, t)$ of the DT discharge is higher than the predicted values using the calculated heating profiles for that discharge (including the alpha heating), and assuming that $\chi_{e}(r, t)$ was held constant at the value obtained in the DD plasma. However, a consistent trend toward improved $\chi_{e}^{\text {tot }}$ in DT plasmas does not appear in the other scans. While the reduction in $\chi_{e}^{\text {tot }}$ in scan $\mathrm{C} 1$ is larger than the estimated experimental precision, the change is not larger than the observed shot-to-shot variation. In addition, the Thomson scattering $T_{e}(R)$ profile measurement shows a consistently smaller increase in $T_{e o}$ between DD and DT plasmas than is measured by ECE. By contrast, $D_{e}$ is consistently reduced over most of the plasma cross section by an amount comparable to the difference in $\chi_{i}^{\text {tot }}$.

These trends are summarized in Fig. 7 , which plots the ratio of $\chi_{i}^{\text {tot }}$ and $D_{e}$ to the corresponding value in the reference DD plasma at the plasma half-radius. The left-hand column of graphs have as the $\mathrm{x}$-axis the fraction of tritium beam power. The right-hand graphs illustrate the power-law fit to the mass scaling of the diffusivities. A favorable dependence of $\chi_{i}^{\text {tot }}$ and $D_{e}$ on $\langle A\rangle$ is obtained, $\chi_{i}^{\text {tot }} \propto\langle A\rangle^{-1.4}$ and $D_{e} \propto\langle A\rangle^{-1.0}$.

Similar regression analysis was carried out for other local plasma parameters, transport coefficients, and confinement times at a variety of minor radii. Tables 3 and 4 present the results of this study. In all cases, the regression includes data only from scans A1, A2, B1, B2, and $\mathrm{C} 1$ at 3.45-3.60 seconds. The regressions confirm improved core ion heating (15-19\%), core electron heating (5-10\%), increased thermal ion stored energy (23\%), electron stored energy (12\%), edge electron density (13\%), and negligible change in core electron density and $Z_{\text {eff }}$ with increasing tritium beam fraction. By construction, there was little correlation of total beam power $\left(\Delta P_{b} \approx 2 \%\right)$ with the tritium beam power fraction. There was virtually no increase in the edge ion temperature $(r / a=0.92)$ with tritium concentration. Thus, the improved ion performance in DT plasmas cannot be attributed to changes in edge $T_{i}$, which has been previously identified as a parameter which correlates well with crre ion energy 
$\chi_{i}^{\text {tot } /(D T)} / \chi_{i}^{\text {tot }}(D)$
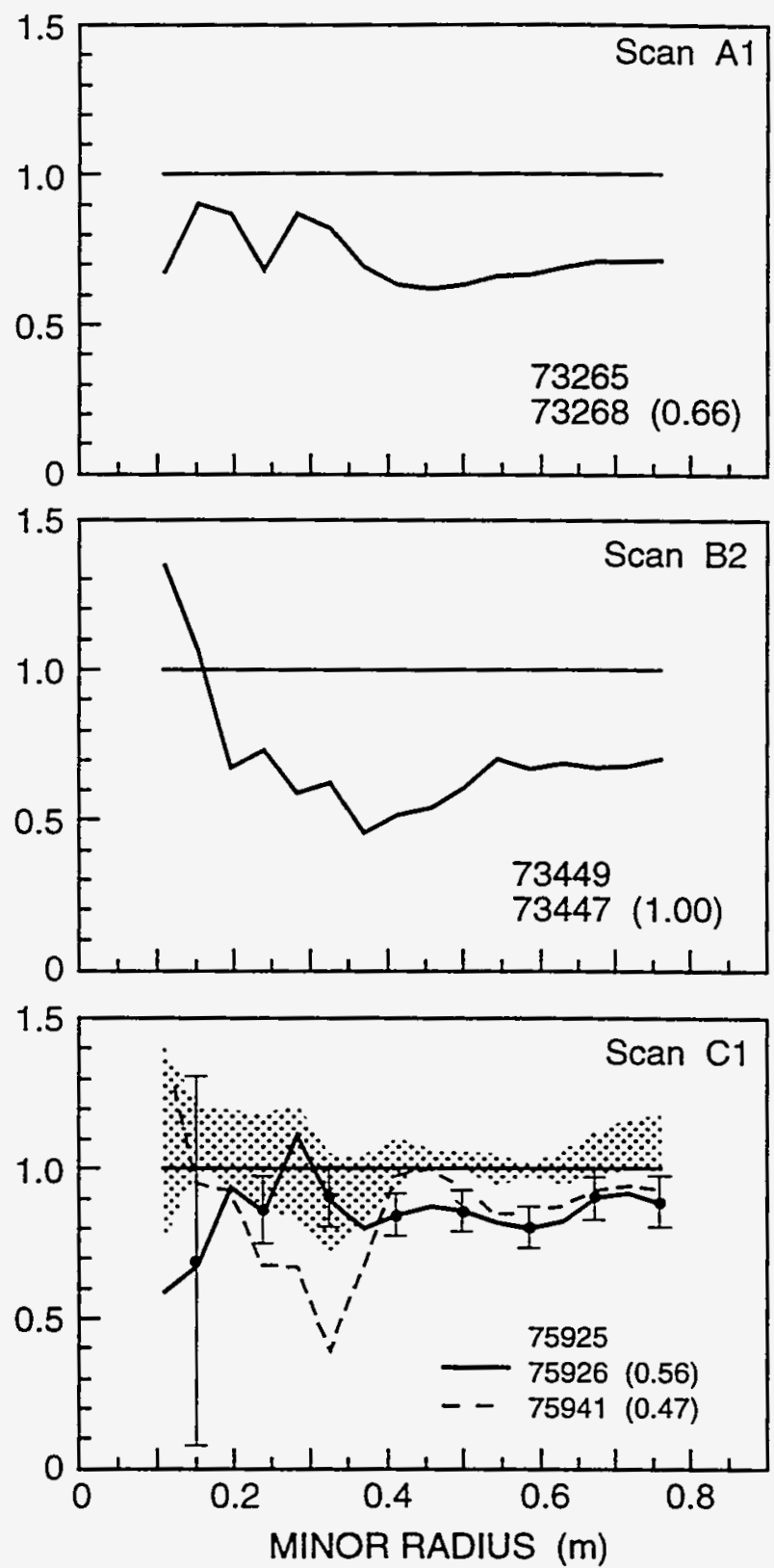

$D_{e}(D T) / D_{e}(D)$
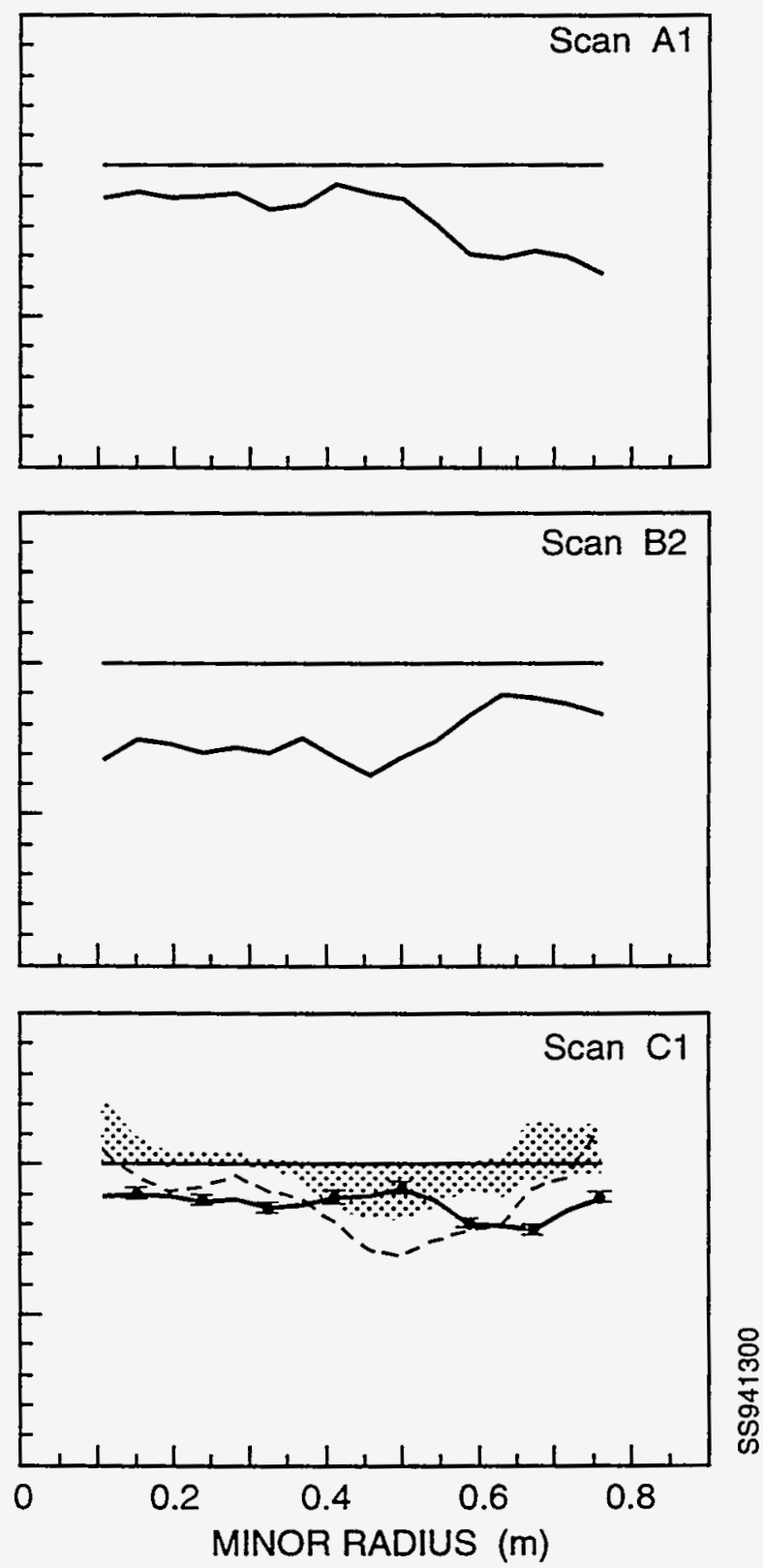

Figure 6: $\chi_{i}^{\text {tot }}$ and $D_{e}$ as a function of minor radius, normalized to their profile values in reference DD plasmas. The shaded regions show the $1-\sigma$ variation of the transport coefficients in deuterium plasmas. The error bars for scan $\mathrm{C} 1$ represent the estimated precision of the transport coefficient ratios between DD and DT plasmas. Each DT shot number is followed by its fraction of tritium beam power in parentheses. 
confinement[6,7].

Since the DT plasmas experience a substantial increase in central thermal ion energy (24\%) without much change in total heating power (1-3\%), the core ion energy confinement time is inferred to increase substantially, corresponding to a scaling $\tau_{E i}(a / 2) \propto\langle A\rangle^{0.69}$. The corresponding scaling of $\tau_{E e}(a / 2)$ is considerably weaker, increasing only as $\langle A\rangle^{0.25}$. The overall thermal energy confinement time determined from kinetic analysis has an isotopic dependence $\tau_{e i} \propto\langle A\rangle^{0.52}$, similar to that of the total kinetic energy confinement time (including beam-ion stored energy), $\tau_{E}^{t o t} \propto\langle A\rangle^{0.59}$. The "steady-state" magnetics analysis implies a weaker isotopic scaling $\left(\propto\langle A\rangle^{0.41}\right)$ than the kinetic analysis $\left(\propto\langle A\rangle^{0.59}\right)$, reflecting the fact that the increase in $W_{\text {tot }}$ observed by magnetic analysis is smaller than that from kinetic analysis.

The uncertainties and correlation coefficients shown in Tables 3 and 4 reflect only the shot-to-shot variability of the parameters listed, and do not include additional uncertainties arising from diagnostic errors. It is not surprising that parameters such as $Z_{\text {eff }}$ which correlate weakly with tritium beam power fraction (less than $1 \%$ change) have a weak correlation coefficient $\left(R^{2}=0.09\right)$, since weak correlations are, by definition, easily obscured by small uncontrolled variations in other parameters. However, the quality of fit is also only moderately good for parameters such as central ion temperature, $\chi_{i}^{\text {tot }}$, and total stored ion energy, all of which are inferred to have a stronger dependence $(\Delta=12-35 \%)$ on plasma composition. This reflects the fairly significant shot-to-shot variation illustrated in Fig. 7, which shows improvements in $\chi_{i}^{\text {tot }}(a / 2)$ ranging from almost negligible to $35 \%$ for DT plasmas with comparable amounts of D-NBI and T-NBI heating relative to those with pure D-NBI. Straightforward statistical analysis of the dataset yields relatively small uncertainties (typically $\leq \pm 0.15$ ) for the exponent on $\langle A\rangle$ in the power-law fits of transport parameters shown in Table 4. However, given the limited quality-of-fit and the significant scatter apparent in Fig. 7, we believe that the total uncertainty in the isotopic-mass scaling of transport is larger than that indicated by the statistical analysis. For this reason uncertainties are not quoted for most of the exponents in the power-law fits of Table 4. Future isotope scaling studies will emphasize comparisons of plasmas with pure T-NBI versus pure D-NBI to increase the difference in plasma performance associated with isotopic content relative to the shot-to-shot irreproducibility.

\section{Comparison with Scan C1}

A comparable regression analysis was carried out for a dataset consisting solely of plasmas in scan $\mathrm{Cl}$, which has $T_{i}$ measurements uncompromised by differing isotope in the doping beam used by CXRS. The results for energy confinement times at both the half radius and integrated over the plasma as a whole are very similar to those obtained for the combined scans. In particular, the scaling of $\tau_{E i}(a)$ is virtually identical, while the dataset from scan $\mathrm{C} 1$ indicates a slightly stronger improvement at the half-radius, $\tau_{E i}(a / 2) \propto\langle A\rangle^{0.80}$. There are somewhat greater differences in the inferred scaling of local parameters, with scan $\mathrm{C} 1$ obtaining $\chi_{i}^{\text {tot }} \propto\langle A\rangle^{-0.6}$ at both the third and half-radius, compared to $\chi_{i}^{\text {tot }} \propto\langle A\rangle^{-1.4}$ at the half-radius for the combined dataset. Determining whether the isotope scaling of local $\chi_{i}^{\text {tot }}$ lies closer to the bottom or top end of this range will be the subject of future experiments. Overall, the results from scan $\mathrm{C} 1$ confirm that local ion energy transport is improved in DT plasmas relative to DD plasmas, indicating that the effect observed in the other scans is not an artifact of spurious ion temperature profile measurements.

\section{Comparison with Thomson Scattering}

The ECE $T_{e}$ profile measurement is narrower than that measured by Thomson scattering and larger at the center, being 1-1.7 keV higher than the Thomson scattering measurement at the plasma center and $\sim 0.8 \mathrm{keV}$ smaller at $R=3.10 \mathrm{~m}$. There is only a modest effect on the 

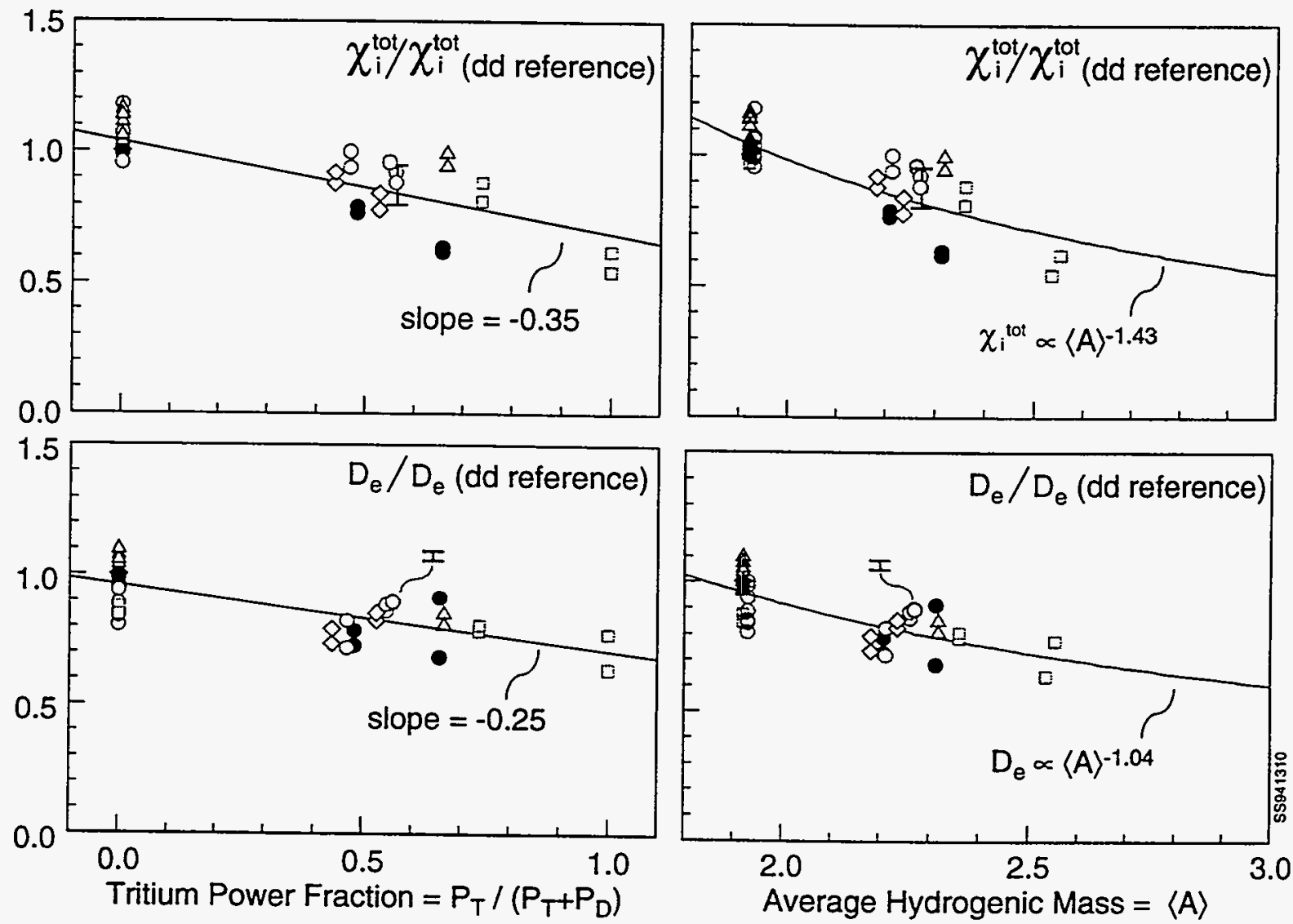

Figure 7: Ratio of local transport coefficients in DT and DD plasmas to those in the reference DD plasma at $r=a / 2$. (a-b) Ratio as a function of tritium beam power fraction. (c-d) Ratio as a function of average hydrogenic mass. 


\begin{tabular}{||l|c|l|l|}
\hline Quantity & & $\begin{array}{l}\text { Variation with } \\
\text { Power Fraction }\end{array}$ & $R^{2}$ \\
\hline \hline$P_{b}$ & $1.00 a$ & $1.00+0.02(01) P_{t} / P_{b}$ & 0.03 \\
$Z_{\text {eff }}$ & & $1.01-0.01(01) P_{t} / P_{b}$ & 0.09 \\
$F_{n e}$ & & $0.99-0.08(01) P_{t} / P_{b}$ & 0.37 \\
\hline$T_{i}$ & 0 & $1.00+0.12(03) P_{t} / P_{b}$ & 0.30 \\
& $0.32 a$ & $0.99+0.19(03) P_{t} / P_{b}$ & 0.46 \\
& $0.52 a$ & $1.00+0.15(03) P_{t} / P_{b}$ & 0.62 \\
& $0.92 a$ & $1.01-0.02(01) P_{t} / P_{b}$ & 0.04 \\
\hline$T_{e}$ & 0 & $1.00+0.10(02) P_{t} / P_{b}$ & 0.40 \\
& $0.52 a$ & $1.00+0.05(02) P_{t} / P_{b}$ & 0.18 \\
& $0.82 a$ & $1.01+0.06(02) P_{T} / P_{b}$ & 0.14 \\
\hline$n_{e}$ & 0 & $1.00-0.002(016) P_{t} / P_{b}$ & 0.00 \\
& $0.52 a$ & $1.01+0.08(02) P_{t} / P_{b}$ & 0.35 \\
& $0.92 a$ & $1.00+0.13(02) P_{t} / P_{b}$ & 0.54 \\
\hline$W_{i}$ & $0.52 a$ & $1.00+0.24(04) P_{t} / P_{b}$ & 0.41 \\
& $1.00 a$ & $1.00+0.23(04) P_{t} / P_{b}$ & 0.44 \\
\hline$W_{e}$ & $0.52 a$ & $1.02+0.11(02) P_{t} / P_{b}$ & 0.33 \\
& $1.00 a$ & $1.01+0.12(02) P_{t} / P_{b}$ & 0.36 \\
\hline$W_{\text {beam }}$ & $0.52 a$ & $1.00+0.16(01) P_{t} / P_{b}$ & 0.77 \\
& $1.00 a$ & $1.00+0.19(01) P_{t} / P_{b}$ & 0.85 \\
\hline \hline
\end{tabular}

Table 3: Scaling of plasma heating and confinement with fraction of tritium beam power. Expressions show the scaling of each quantity normalized to its value in reference deuterium-only comparison plasmas from Scans $\mathrm{A} 1, \mathrm{~A} 2, \mathrm{~B} 1, \mathrm{~B} 2, \mathrm{C} 1$ at $3.44-3.62 \mathrm{sec}$.

\begin{tabular}{||l|l|l|l|l||}
\hline Quantity & & $\begin{array}{l}\text { Variation with } \\
\text { Power Fraction }\end{array}$ & Variation with $\langle A\rangle$ & $R^{2}$ \\
\hline \hline$W_{\text {tot }}^{\text {mag }} /\left(P_{b}+P_{O H}\right)$ & $1.00 a$ & $1.00+0.16(01) P_{t} / P_{b}$ & $0.71\langle A\rangle^{0.54 \pm .04}$ & 0.75 \\
$W_{\text {tot }}^{\text {mag }} /\left(P_{b}+P_{O H}+P_{\alpha}\right)$ & $1.00 a$ & $1.00+0.12(01) P_{t} / P_{b}$ & $0.77\langle A\rangle^{0.41 \pm .04}$ & 0.67 \\
\hline$\tau_{E}^{t o t}$ (kinetic) & $1.00 a$ & $1.00+0.18(01) P_{t} / P_{b}$ & $0.68\langle A\rangle^{0.59 \pm .04}$ & 0.83 \\
\hline$\tau_{E}^{t h}$ (kinetic) & $0.52 a$ & $1.00+0.16(02) P_{t} / P_{b}$ & $0.72\langle A\rangle^{0.51}$ & 0.46 \\
& $1.00 a$ & $1.00+0.16(02) P_{t} / P_{b}$ & $0.71\langle A\rangle^{0.52}$ & 0.53 \\
\hline$\tau_{E i}$ & $0.52 a$ & $0.99+0.22(04) P_{t} / P_{b}$ & $0.63\langle A\rangle^{0.69}$ & 0.40 \\
& $1.00 a$ & $0.99+0.17(03) P_{t} / P_{b}$ & $0.70\langle A\rangle^{0.54}$ & 0.35 \\
\hline$\tau_{E e}$ & $0.52 a$ & $1.02+0.08(02) P_{t} / P_{b}$ & $0.86\langle A\rangle^{0.25}$ & 0.29 \\
& $1.00 a$ & $1.00+0.14(02) P_{t} / P_{b}$ & $0.75\langle A\rangle^{0.46}$ & 0.46 \\
\hline$\tau_{p e}$ & $0.52 a$ & $1.01+0.34(01) P_{t} / P_{b}$ & $0.50\langle A\rangle^{1.07 \pm .03}$ & 0.96 \\
& $1.00 a$ & $1.00+0.25(01) P_{t} / P_{b}$ & $0.59\langle A\rangle^{0.80 \pm .04}$ & 0.90 \\
\hline$\chi_{i}^{\text {tot }}$ & $0.52 a$ & $1.04-0.35(05) P_{t} / P_{b}$ & $2.65\langle A\rangle^{-1.43}$ & 0.61 \\
$\chi_{e}^{\text {tot }}$ & $0.52 a$ & $0.98-0.09(03) P_{t} / P_{b}$ & $1.23\langle A\rangle^{-0.35}$ & 0.15 \\
$D_{e}$ & $0.52 a$ & $0.96-0.25(03) P_{t} / P_{b}$ & $1.89\langle A\rangle^{-1.04}$ & 0.55 \\
\hline
\end{tabular}

Table 4: Scaling of local diffusivities with fraction of tritium beam power and with average thermal hydrogenic mass, based on ECE measurements of $T_{e}$ in scans A1, A2, B1, B2, and C1 (3.44-3.62 sec). Expressions show the scaling of each quantity normalized to its value in reference deuterium-only comparison plasmas. 
inferred $\chi_{i}^{\text {tot }}$, because changes in $T_{e}$ only affect the ion analysis through the ion-electron power coupling, which is a relatively small term in the ion power balance. Transport analysis based on the Thomson scattering measurements of $T_{e}(R)$ imply a somewhat stronger favorable scaling of $\chi_{i}^{\text {tot }}$ with $\langle A\rangle$ than do the ECE measurements, while $\chi_{e}^{\text {tot }}$ is inferred to have an unfavorable isotopic dependence. Thus with the data currently available it is difficult to reach a definitive conclusion regarding the isotopic scaling of electron heat transport in supershot plasmas.

\section{Discussion}

The regression analysis reported here simply correlates various measures of energy confinement $\left(\tau_{E}, \chi_{i}^{\text {tot }}\right.$, etc.) with tritium concentration. Because the DT plasmas had better confinement than the DD plasmas, their parameters are not exactly matched, in particular the DT plasmas have higher $T_{i}$. A favorable causal dependence of $\chi_{i}^{\text {tot }}$ on $T_{i}$ (or correlated parameters such as $T_{i} / T_{e}$ or $\beta$ ) in supershot plasmas would amplify any intrinsic isotopic scaling, and might give rise to the observed "strength" of the isotope effect in the ion channel in $\mathrm{DD} / \mathrm{DT}$ comparisons at constant heating power, even if the intrinsic dependence were weak. We have previously observed a favorable scaling of $\chi_{i}^{\text {tot }}$ with $T_{i}[8,7]$ in DD supershot plasmas, with $\chi_{i}^{\text {tot }}$ falling roughly as $1 / T_{i}$ at the $r=a / 3$ in scans of heating power at constant $I_{p}$. The DT scans discussed here span a modest range in heating power, collectively ranging from 20-30 MW. Although there is some overlap between the ion temperatures in the lower-power DT plasmas and the higher-power DD plasmas, we have not unambiguously isolated the isotope dependence of $\chi_{i}^{\text {tot }}$ and $\tau_{E i}$ from additional dependences on local $T_{i}$ or $T_{i} / T_{e}$.

Previous L-mode heating experiments[9] compared deuterium beam injection into deuterium and hydrogen target plasmas at heating power up to $7 \mathrm{MW}$, spanning about the same range of isotope mix as explored in these $\mathrm{DT}$ experiments (the nominally hydrogen plasmas were typically not more than $\sim 65 \%$ hydrogen). These plasmas had $T_{i} \approx T_{e}$. The deuterium plasmas achieved 8-10\% more thermal stored energy than comparable hydrogen plasmas at the same heating power, which implied a relatively weak isotopic scaling $\tau_{E}^{\text {th }} \propto\langle A\rangle^{0.24}[10]$. In contrast to the supershot results, the L-mode plasmas experienced a larger isotopic effect on electron stored energy than on ion stored energy between hydrogen and deuterium plasmas. No differences in the central momentum density were observed during unidirectional beam injection into hydrogen and deuterium L-mode plasmas, suggesting a negligible or weak isotopic effect on $\chi_{\phi}$ in that regime.

\section{Conclusion}

A series of controlled heating experiments on the TFTR tokamak has demonstrated improved energy confinement in plasmas heated and fueled by tritium neutral beams compared to deuterium neutral beams. The maximum increase in total plasma stored energy measured by magnetic diagnostics was $22 \%$ for comparable plasma conditions. Regression analysis of a number of controlled scans which varied the fraction of tritium beam power obtained a best-fit increase of $21 \%$ in $\tau_{E}^{\text {tot }}$ (magnetic) between pure deuterium and pure tritium beam injection. This corresponds to an isotopic scaling $\tau_{E}^{t o t} \propto\langle A\rangle^{0.67}$, or $\tau_{E}^{t o t} \propto\langle A\rangle^{0.54}$ if the additional heating by alpha particles is included.

The kinetic analysis indicates that up to $60 \%$ of the increase in $W_{\text {tot }}$ was due to higher stored energy in the thermal ions and electrons, particularly the ions. The thermal ions experienced a $20-25 \%$ increase in central temperature and a comparable increase in stored energy between plasmas heated with pure deuterium versus pure tritium beams. Because 
changes in the beam power deposition profile to ions were small, the larger energy ion thermal energy implies improved ion energy confinement in the DT plasmas, $\tau_{E i}(a / 2) \propto\langle A\rangle^{0.69}$. These experiments have not tested whether a favorable dependence of $\tau_{E i}$ on $T_{i}$ in supershot plasmas amplifies a weaker, intrinsic isotope dependence.

Local electron particle transport was also inferred to be $20-30 \%$ smaller in the most tritium-rich plasmas compared to reference DD plasmas. Although reduced $\chi_{e}^{\text {tot }}$ was obtained in some DT versus DD shot-pair comparisons, the magnitude of the reduction in $\chi_{e}^{\text {tot }}$ was only comparable to the shot-to-shot variation obtained in nominally identical DD plasmas, and it was not consistently observed. In addition, electron temperature profile measurements by Thomson scattering showed a smaller $T_{e}$ increase than did measurements by ECE diagnostics.

Additional studies to improve our understanding of isotopic scaling of local transport will be pursued during the remainder of the DT campaign on TFTR. These include (a) beam power scans, to distinguish isotope effects from temperature scaling of $\chi_{i}^{\text {tot }} ;(\mathrm{b})$ uni-directional beam heating, to determine the isotopic scaling of $\chi_{\phi} ;$ (c) operation in regimes having $T_{i} \approx T_{e}$; and (d) measurements of density fluctuations in DD and DT plasmas by beam emission spectroscopy and correlation reflectometry.

\section{ACKNOWLEDGEMENTS}

This work was supported by the U.S. DOE contract number DE-AC02-76-CHO-3073. The authors gratefully acknowledge the contributions from the technical staff of the Princeton Plasma Physics Laboratory, by participants from U.S. and international laboratories, universities, and industries, and the continuing support of P. Rutherford and R. Davidson. 


\section{References}

[1] STRACHAN, J. D., BITTER, M., RAMSEY, A. T., ZARNSTORFF, M. C., ARUNASALAM, V., et al., Phys. Rev. Lett. 58 (1987) 1004.

[2] CHANG, Z., FREDRICKSON, E. D., CALLEN, J. D., MCGUIRE, K. M., BELL, M. G., et al., Nucl. Fusion (1994), Accepted for publication by Nuclear Fusion. (Princeton University Plasma Physics Laboratory Report PPPL-2941 (1993)).

[3] TOWNER, H., GOLDSTON, R., HAMMETT, G., MURPHY, J., PHILLIPS, C., et al., Rev. Sci. Instrum. 63 (1992).

[4] STRACHAN, J. D., ADLER, H., ALLING, P., ANCHER, C., ANDERSON, H., et al., Phys. Rev. Lett. 72 (1994) 3526.

[5] HAWRYLUK, R. J., ADLER, H., ALLiNG, P., ANCHER, C., ANDERSON, H., et al., Phys. Rev. Lett. 72 (1994) 3530.

[6] SCOTT, S. D., MCCUNE, D. C., BELL, M. G., BELL, R., BUDNY, R. V., et al., Recycling perturbations of supershot plasmas, in Proceedings of the 19th European Conference on Controlled Fusion and Plasma Physics, volume 16C of Europhysics Conference Abstracts, Petit-Lancy, 1992, EPS, Part I.

[7] SCOTT, S. D., BARNES, C. W., ERNST, D., SCHIVELL, J., SYNAKOWSKI, E. J., et al., Parametric variations of ion transport in TFTR, in HORTON, W., WOOTTON, A., and WAKATANI, M., editors, Proceedings of the U.S.-Japan Workshop on Ion Temperature Gradient Driven Turbulent Transport, University of Texas at Austin, January 11-14, 1993., AIP conference proceedings 284, chapter 2, AIP Press, 1994.

[8] MEADE, D. M. et al., Recent TFTR results, in Plasma Physics and Controlled Nuclear Fusion Research, 1990, volume 1, pp. 9-24, IAEA, Vienna, 1991, (Washington, D.C. Conference).

[9] BARNES, C. W., SCOTT, S. D., BELL, M. G., BELL, R., BUDNY, R. V., et al., Energy confinement analysis of hydrogen isotope experiments on TFTR, manuscript in preparation.

[10] HAWRYLUK, R. J. et al., Plasma Phys. Controlled Fusion 33 (1991) 1509. 
Dr. F. Paoloni, Univ, of Wollongong, AUSTRALIA

Prof. R.C. Cross, Univ. of Sydney, AUSTRALIA

Plasma Research Lab., Australian Nat. Univ., AUSTRALIA

Prof. I.R. Jones, Flinders Univ, AUSTRALIA

Prof. F. Cap, Inst. for Theoretical Physics, AUSTRIA

Prof. M. Heindler, institut för Theoretische Physik, AUSTRIA

Prof. M. Goossens, Astronomisch Instituut, BELGIUM

Ecole Royale Militaire, Lab. de Phy. Plasmas, BELGIUM

Commission-European, DG. XII-Fusion Prog., BELGIUM

Prof. R. Bouciqué, Rijksuniversiteit Gent, BELGIUM

Dr. P.H. Sakanaka, Instituto Fisica, BRAZIL

Prof. Dr. I.C. Nascimento, Instituto Fisica, Sao Paulo, BRAZIL Instituto Nacional De Pesquisas Espaciais-INPE, BRAZIL Documents Office, Atomic Energy of Canada Ltd., CANADA

Ms. M. Morin, CCFMTokamak de Varennes, CANADA

Dr. M.P. Bachynski, MPB Technologies, Inc., CANADA

Dr. H.M. Skarsgard, Univ. of Saskatchewan, CANADA

Prof. J. Teichmann, Univ. of Montreal, CANADA

Prof. S.R. Sreenivasan, Univ. of Calgary, CANADA

Prof. T.W. Johnston, INAS-Energie, CANADA

Dr. R. Bolton, Centre canadien de fusion magnétique, CANADA

Dr. C.R. James, Univ. of Alberta, CANADA

Dr. P. Lukác, Komenského Universzita, CZECHO-SLOVAKIA

The Librarian, Culham Laboratory, ENGLAND

Library, R61, Rutherford Appleton Laboratory, ENGLAND

Mrs. S.A. Hutchinson, JET Library, ENGLAND

Dr. S.C. Sharma, Univ. of South Pacific, FIJI ISLANDS

P. Mähönen, Univ. of Helsinki, FINLAND

Prof. M.N. Bussac, Ecole Polytechnique,, FRANCE

C. Mouttet, Lab. de Physique des Milieux lonisés, FRANCE

J. Radet, CEN/CADARACHE - Bat 506, FRANCE

Prof. E. Economou, Univ. of Crete, GREECE

Ms. C. Rinni, Univ. of loannina, GREECE

Preprint Library, Hungarian Academy of Sci., HUNGARY

Dr. B. DasGupta, Saha inst. of Nuclear Physics, INDIA

Dr. P. Kaw, Inst. for Plasma Research, INDIA

Dr. P. Rosenau, Israel Inst. of Technology, ISRAEL

Librarian, Intemational Center for Theo Physics, ITALY

Miss C. De Palo, Associazione EURATOM-ENEA, ITALY

Dr. G. Grosso, Istituto di Fisica del Plasma, ITALY

Prof. G. Rostangni, Istituto Gas lonizzati Del Cnr, ITALY
Dr. H. Yamato, Toshiba Res \& Devel Center, JAPAN

Prof. I. Kawakami, Hiroshima Univ., JAPAN

Prof. K. Nishikawa, Hiroshima Univ., JAPAN

Librarian, Naka Fusion Research Establishment, JAERI, JAPAN

Director, Japan Atomic Energy Research Inst., JAPAN

Prof. S. Itoh, Kyushu Univ., JAPAN

Research Info. Ctr., National Instit. for Fusion Science, JAPAN

Prof. S. Tanaka, Kyoto Univ., JAPAN

Library, Kyoto Univ., JAPAN

Prof. N. Inoue, Univ. of Tokyo, JAPAN

Secretary, Plasma Section, Electrotechnical Lab., JAPAN

Dr. O. Mitarai, Kumamoto Inst. of Technology. JAPAN

Dr. G.S. Lee, Korea Basic Sci. Ctr., KOREA

J. Hyeon-Sook, Korea Atomic Energy Research Inst., KOREA

D.I. Choi, The Korea Adv. Inst. of Sci. \& Tech., KOREA

Prof. B.S. Liley, Univ. of Waikato, NEW ZEALAND

Inst of Physics, Chinese Acad Sci PEOPLE'S REP. OF CHINA

Library, Inst. of Plasma Physics, PEOPLE'S REP. OF CHINA

Tsinghua Univ. Library, PEOPLE'S REPUBLIC OF CHINA

Z. Li, S.W. Inst Physics, PEOPLE'S REPUBLIC OF CHINA

Prof. J.A.C. Cabral, Instituto Superior Tecnico, PORTUGAL

Prof. M.A. Hellberg, Univ. of Natal, S. AFRICA

Prof. D.E. Kim, Pohang Inst. of Sci. \& Tech., SO. KOREA

Prof. C.I.E.M.A.T, Fusion Division Library, SPAIN

Dr. L. Stenflo, Univ. of UMEA, SWEDEN

Library, Royal Inst. of Technology, SWEDEN

Prof. $H$. Wilhelmson, Chalmers Univ. of Tech., SWEDEN

Centre Phys. Des Plasmas, Ecole Polytech, SWITERLAND

Bibliotheek, Inst. Voor Plasma-Fysica, THE NETHERLANDS

Asst. Prof. Dr. S. Cakir, Middle East Tech. Univ., TURKEY

Dr. V.A. Glukhikh,Sci. Res. Inst. Electrophys.l Apparatus, USSR

Dr. D.D. Ryutov, Siberian Branch of Academy of Sci., USSR

Dr. G.A. Eliseev, I.V. Kurchatov Inst., USSR

Librarian, The Ukr.SSR Academy of Sciences, USSR

Dr. L.M. Kovrizhnykh, Inst. of General Physics, USSR

Kernforschungsanlage $\mathrm{GmbH}$, Zentralbibliothek, W. GERMANY

Bibliothek, Inst. Für Plasmaforschung, W. GERMANY

Prof. K. Schindler, Ruhr-Universitát Bochum, W. GERMANY

Dr. F. Wagner, (ASDEX), Max-Planck-Institut, W. GERMANY

Librarian, Max-Planck-Institut, W. GERMANY 